\title{
DA MANUFATURA À MAQUINARIA MODERNA: A SUBSUNÇÃO REAL DO TRABALHO AO CAPITAL
}

\section{FROM MANUFACTURE TO MODERN MACHINERY: SUBSUMING REAL LABOR UNDER CAPITAL}

\author{
Osmar Martins de Souza ${ }^{1}$ \\ José Joaquim Pereira Melo ${ }^{2}$ \\ Renan Willian Fernandes Gomes ${ }^{3}$
}

\section{RESUMO}

O presente texto tem como intento discutir sobre o processo de transformação que ocorreu no modo de produção capitalista com a passagem da manufatura à indústria moderna, pois essa modificação na forma de produção, possibilitou a transição da subsunção formal para a subsunção real do trabalho ao capital. Para compreender essa modificação, recorreu-se, principalmente, à análise que Karl Marx desenvolveu em sua principal obra: O Capital: crítica da economia política. Nesta obra, o autor escreveu dois capítulos intitulados: Divisão do trabalho e manufatura e A maquinaria e a indústria moderna, nos quais procurou explicar historicamente que a transição da manufatura à indústria moderna foi o meio fundamental para a subsunção real do trabalho ao capital e para consolidação do modo capitalista de produção. A partir disto, o sistema capitalista tornou-se o modo de produção hegemônico, pois teve condições materiais para aumentar a produtividade do trabalho, o lucro e remover os entraves que a produção manufatureira impunha à expansão do capital.

Palavras-chave: Manufatura - Maquinaria - Trabalho - Capitalismo.

\section{ABSTRACT}

This paper aims at discussing the transformative process taking place amidst the rise of the capitalist mode of production, as a result of the substitution of manufacture for modern machinery. Bearing the capital in mind, the aforementioned process made it possible to switch from the subsuming formality of labor to a real subsuming one. In order to comprehend that modification, this work veers into Marx's analyses expressed in Capital: a critique of political economy. In his book, the author wrote two chapters entitled: The division of labor and manufacture and Machinery and modern industry, in which he, under a historical perspective, sets out that the transition from manufacture to modern industry was a paramount factor to indeed subsume labor under capital furthermore, that undergirded the capitalist mode of production. Since which point on, the capitalist system became a hegemonic mode of production, given the fact that it had material conditions/means to increase labor productivity and profits as well as remove manufacture, once the latter hindered the expansion of capital.

Keywords: Manufacture - Machinery - Labor - Capitalism. 


\section{INTRODUÇÃO}

A subsunção real do trabalho no capital desenvolve-se em todas aquelas formas que produzem mais-valia relativa, ao contrário de absoluta (MARX, 1975, p. 89).

Neste texto, tem-se a intenção de discutir o processo de transformação que ocorreu no modo de produção capitalista com a passagem da manufatura à indústria moderna, pois essa modificação na forma de produção possibilitou a transição da subsunção formal para a subsunção real do trabalho ao capital. Essa discussão terá como referencial a análise que Karl Marx ${ }^{4}$ desenvolveu na sua principal obra, O Capital: crítica da economia política, nos capítulos, Divisão do trabalho e manufatura e $\boldsymbol{A}$ maquinaria e a indústria moderna. A partir dessa mudança na forma de produção, o capitalismo consolidou-se como modo de produção hegemônico, pois submeteu o trabalhador aos seus interesses, teve condições materiais para aumentar a produtividade e remover os entraves que a produção manufatureira impunha à extração de mais-valia ${ }^{5}$. Nesse sentido, são expressivas as afirmações de Marx:

Com a subordinação real do trabalho no capital efectua-se uma revolução total (que prossegue e se repete continuamente) no próprio modo de produção, na produtividade do trabalhado e na relação entre capitalista e operário (MARX, 1975, p. 89).

Com a introdução das máquinas-ferramenta na produção, o capital subsumiu não só formalmente, mas efetivamente o trabalho aos seus ditames e pode aumentar a sua exploração com a extração de mais-valia relativa, ou seja, encurtando a parte do dia que o trabalhador trabalha para si, e aumentando a parte que ele trabalha para $o$ capital.

Por isso, no capitalismo, busca-se, constantemente, fomentar o desenvolvimento de novos conhecimentos científicos para aplicá-los no desenvolvimento de novos instrumentos de produção com o objetivo de ampliar a acumulação de capital e o domínio da burguesia.

Nessa perspectiva, argumenta Marx e Engels no Manifesto do Partido Comunista: 
A burguesia não pode existir sem revolucionar continuamente os instrumentos de produção e, por conseguinte, as relações de produção, portanto todo o conjunto das relações sociais. A conservação inalterada do antigo modo de produção era, ao contrário, a primeira condição de existência de todas as classes industriais anteriores. O contínuo revolucionamento da produção, 0 abalo constante de todas as condições sociais, a incerteza e a agitação eternas distinguem a época burguesa de todas as precedentes (MARX; ENGELS, 1996, p. 69).

O desenvolvimento de novos instrumentos de produção é uma necessidade constante do sistema capitalista, que procura maximizar a produção e minimizar o tempo gasto para produzir mercadorias. Esse processo só se tornou possível, na medida em que se desenvolveram conhecimentos com vistas à expansão da produção. Assim, esses conhecimentos tornaram possível a introdução da maquinaria na produção, que, por sua vez, revolucionou a estrutura produtiva da sociedade, com base na manufatura. A força de trabalho vivo era o alicerce da produção manufatureira, e o emprego de máquinas na produção demoliu esse fundamento, pois colocou o trabalhador apenas como um meio. Esse processo de desqualificação do trabalho vivo foi paulatinamente se efetivando, mas não pode ser pensado e nem compreendido, sem colocar na ordem do dia as contradições sociais que se evidenciaram a partir do desenvolvimento da indústria moderna.

\section{DA MANUFATURA À INDÚSTRIA MODERNA: DA SUBSUNÇÃO FORMAL À SUBSUNÇÃO REAL DO TRABALHO AO CAPITAL}

Com o desenvolvimento das forças produtivas, patrocinadas pelo capital, intensificou-se a desvalorização do trabalhador, e sua exploração alcançou níveis desumanos. Essa situação produziu as contradições entre burgueses e proletários e gerou os principais conflitos de classes no século XIX, em diversos países da Europa. Esse quadro de conflitos torna-se compreensível quando se analisa essa sociedade, levando em consideração as contradições que são inerentes a sua própria essência. Ela subordina, constantemente, o trabalho real às necessidades do capital, gerando a sua própria autodeterminação, e, dentro desse processo, o trabalhador passa a ser apenas uma peça no processo de produção (MAZZUCHELLI, 1985, p. 18). Por isso, a 
afirmativa de que as contradições são inerentes ao sistema de acumulação da sociedade capitalista.

O movimento de acumulação de capital, na medida em que implica elevação contínua da produtividade do trabalho e elevação contínua de composição técnica e orgânica do capital; na medida em que se funda numa base técnica em que a arte produtiva está concentrada no capital e plasmada nas máquinas, o que determina a desqualificação e o entorpecimento do trabalho vivo; na medida em que avança progressivamente, destruindo formas pretéritas de produção e tornando "livres" os produtos diretos - o movimento de acumulação, por sua própria dinâmica interna, cria não só a demanda como também a oferta de trabalho [...] (MAZZUCCHELLI, 1985, p. 19).

Com o desenvolvimento e aplicação da máquina na produção de mercadorias, promoveu-se a superação da forma de produção manufatureira de mercadorias, e com essa substituição na produção, o capital subsumiu o trabalho aos seus interesses. A produção manufatureira tinha como referencial a força de trabalho vivo e dependia quase que exclusivamente desta. A maquinaria moderna foi substituindo o que era considerado o centro da produção na manufatura (o homem) e, com isso, foi promovendo uma verdadeira transformação na sociedade, pois provocou a independência em relação ao trabalho vivo. Na grande indústria, o capital subordina por inteiro (formal e realmente) o trabalho pelo controle do processo de trabalho: o trabalhador passa a ser apenas um apêndice das máquinas (NETTO; BRAZ, 2007, p. 112).

A esse respeito afirma Benedito R. Moraes Neto:

A montagem do grande autômato, objetivando o processo do trabalho pela via do sistema de máquinas, pela incorporação da ciência através sistema de máquinas. A façanha do capital, no sentido de moldar o processo de trabalho às suas determinações, descrita por Marx, vem a ser a subordinação do trabalho vivo ao trabalho morto. A ação do capital se dá pelo lado dos elementos objetivos do processo de trabalho: 'na manufatura, a revolução operada no regime de produção tem como ponto de partida a força de trabalho; na grande indústria, o instrumento de trabalho' (MORAES NETO, 1989, p. 28).

Nesse sentido, para entender essa dinâmica do modo de produção capitalista, torna-se fundamental retroceder aos escritos de Marx, pois a sua análise materialista do desenvolvimento da sociedade burguesa é a que melhor explica o seu nascimento, a sua expansão e a possibilidade de sua superação. Em $A$ ideologia 
Alemã, Marx e Engels enfatizaram a necessidade e a importância de se entender materialmente e não idealmente a sociedade, com as seguintes palavras:

O fato é, portanto, o seguinte: indivíduos determinados, que são ativos na produção de determinada maneira, contraem entre si estas relações sociais e políticas determinadas. A observação empírica tem de provar, em cada caso particular, empiricamente e sem nenhum tipo de mistificação ou especulação, a conexão entre a estrutura social e política e a produção. A estrutura social e o Estado provêm constantemente do processo de vida de indivíduos determinados, mas desses indivíduos não como podem aparecer na imaginação própria ou alheia, mas sim tal como realmente são, quer dizer, tal como atuam, como produzem materialmente e, portanto, tal como desenvolvem suas atividades sob determinados limites, pressupostos e condições materiais, independentes de seu arbítrio. A produção de idéias, de representações, da consciência, está, em princípio, imediatamente entrelaçada com a atividade material e com o intercâmbio material dos homens, com a linguagem da vida real (MARX; ENGELS, 2007, p. 93).

Por isso, a compreensão sobre a passagem da manufatura à maquinaria moderna é uma condição fundamental para o entendimento das principais transformações produtivas introduzidas pelo capital, bem como dos conflitos decorrentes destas modificações na sociedade e suas implicações no campo das idéias (educação/formação). Verse-a que, o que se apresenta como "novo", Marx já tinha sido enfático em seus escritos, marcando os efeitos que a maquinaria moderna trouxe em relação à forma de produção anterior (manufatura) e os resultados para a organização da sociedade. Visualizou que o capitalismo, ao aprofundar o modo de produção capitalista, através do desenvolvimento tecnológico, com a hegemonia da máquina aplicada na produção, iria ocupar progressivamente o espaço de trabalho humano, tornando-os cada vez mais obsoletos e dependentes do capital.

O desenvolvimento da maquinaria e a divisão do trabalho levam o trabalho dos proletários a perder todo caráter independente e com isso qualquer atrativo para o operário. Esse se torna um simples acessório da máquina, do qual só se requer a operação mais simples, mais monótona, mais fácil de aprender (MARX; ENGELS, 1996, p. 72).

Isso posto, a preocupação será em verificar nas conclusões feitas por Marx, nos textos já citados e em outros, que sinalizam a mudança no modo de produção capitalista que marcou a substituição do trabalho vivo pelo trabalho morto. Esses dão o 
fundamento para o entendimento da produção da vida na sociedade contemporânea, pois só através da análise da produção da vida, alicerçada no campo econômico e histórico, dão uma visão totalitária do que se pretende verificar, e da sociedade em geral.

Dado que a maquinaria inaugurou uma nova etapa no sistema capitalista de produção, pretende-se entender esse processo na sua especificidade, marcando o fenecimento do modo anterior e enfatizando as mudanças que vieram à tona a partir das novas conquistas. Não se pode negar que, em certa medida, exista uma continuidade nos acontecimentos, pois não existe evento que não se possa ligar de uma maneira racional aos eventos anteriores e posteriores. Assim, colocando-se no nível mais profundo das estruturas, conseguirá desvendar as rupturas, as grandes transformações, que marcam as mudanças na história da humanidade, que são os momentos de transição. Esses momentos revelam os saltos de desenvolvimento nunca antes vistos (ARRUDA ANDRADE, 1988, p.17). E isso se evidencia de forma plástica com o advento da indústria moderna, pois esta colocou em xeque a organização do modelo de produção baseado na manufatura.

A manufatura pode ser considerada uma forma evoluída de produção, pois intensificou a divisão do trabalho, impulsionando, significativamente, um desenvolvimento na produção e circulação de mercadorias. Porém, ainda era limitada a partir das habilidades dos trabalhadores parciais que determinavam o nível de produção, pois ela dependia, exclusivamente, do desempenho de cada trabalhador em sua função particular na execução de sua tarefa (ARRUDA ANDRADE, 1988, p.17).

Um artífice que executa, uma após outra, as diversas operações parciais da produção de uma mercadoria, é obrigado ora a mudar de lugar, ora a mudar de ferramenta. A passagem de uma operação para outra interrompe o fluxo de seu trabalho e forma por assim dizer lacunas em seu dia de trabalho. Essas lacunas somem quando executa o dia inteiro continuamente uma única operação, ou desaparecem na medida em que diminuem as mudanças de operação. $O$ acréscimo de produtividade se deve então ao dispêndio crescente da força de trabalho, de trabalho num dado espaço de tempo, isto é, à intensidade crescente do trabalho, ou a uma decréscimo do dispêndio improdutivo da força de trabalho. [...] A produtividade do trabalho depende não só da virtuosidade do trabalhador, mas também da perfeição de suas ferramentas. (MARX, 1987, p. 391). 
Um dos princípios característicos da manufatura é a sua extrema divisão do trabalho, privilegiando as diferentes fases da produção e gerando uma relativa independência entre os diversos trabalhadores. Com isso, torna-se necessário uma ponte, de um trabalhador para o outro, que proporcione o contínuo fluxo na produção.

A divisão do trabalho, o princípio característico da manufatura, exige o isolamento das diferentes fases de produção e sua independência recíproca como outros tantos trabalhos parciais de caráter artesanal. Para estabelecer e manter a conexão entre as diferentes funções isoladas, é necessário o transporte ininterrupto do artigo de uma mão para outra e de um processo para outro. Isto representa, confrontando-se com a grande indústria mecanizada, uma limitação peculiar, custosa e imanente ao princípio da manufatura (MARX, 1987, p. 395).

$\mathrm{Na}$ manufatura, o aumento produção se esbarra na própria limitação da divisão social do trabalho e dos mecanismos empregados na fabricação de mercadorias, pois ela é totalmente dependente das qualidades e habilidades de cada indivíduo e das técnicas que são utilizadas (ferramentas), para que haja uma expansão na cadeia produtiva.

O mecanismo específico do período manufatureiro é o trabalhador coletivo, constituído de muitos trabalhadores parciais. As diferentes operações executadas sucessivamente pelo produtor de uma mercadoria e que se entrelaçam no conjunto de seu processo de trabalho, apresentam-lhe exigências diversas. Numa tem ele de desenvolver mais força, nutra mais destreza, numa terceira atenção mais concentrada etc (MARX, 1987, p. 400).

A ferramenta principal na manufatura era a força de trabalho e essa impunha limites à produção que são de ordem natural (físico) e racional (conhecimento do processo produtivo por parte do trabalhador), e chega-se a um momento em que não é mais possível explorar as habilidades do trabalhador e, com isso, a expansão do capital sofreria uma estagnação, contrariando os próprios objetivos do capitalismo. "Fica claro, portanto, que a dependência em relação ao trabalho vivo, enquanto dependência em relação à habilidade do trabalhador manual caracterizava-se um entrave para o império do capital. Era crucial para o modo de produção capitalista se independentizar do trabalho vivo. [...]" (MORAES NETO, 1989, p.27). 
Isto posto, era preciso superar as limitações que a manufatura impunha ao pleno desenvolvimento do capital, através da implantação de novos métodos, que possibilitariam uma ampla produção de mercadorias sem depender exclusivamente do trabalho vivo e das antigas técnicas (ferramentas).

Eric Hobsbawm propõe três condições essenciais que promoveriam uma transformação no modo de produção manufatureiro: uma limitação externa para a expansão dos velhos métodos, que tornavam difícil aumentar a produção além de um certo ponto com os métodos existentes; uma perspectiva de expansão do mercado, tão ampla que justificasse a diversificação e o aperfeiçoamento dos métodos antigos; uma expansão tão rápida do mercado que a simples modificação dos antigos métodos de produção não lhe pudesse fazer frente ( ARRUDA ANDRADE, 1988, p.31).

Com esse quadro, pode-se pensar que as novas exigências impostas pela transformação social (exigências da acumulação de capital) tornaram possível a superação da produção manufatureira e, com isso, a implantação de novas técnicas, plasmada na construção de máquinas, era uma necessidade para o capitalismo prover seus interesses. A produção manufatureira criou condições materiais para promover a revolução industrial e desobstruiu os empecilhos para que o processo de trabalho fosse comandado pela lógica do capital.

Por isso, segundo Marx:

Ela desenvolve a força produtiva do trabalho coletivo para o capitalista, e não para o trabalhador, e, além disso, deforma o trabalhador individual. Produz novas condições de domínio do capital sobre o trabalho. Revela-se, de um lado, progresso histórico e fator necessário do desenvolvimento econômico da sociedade, e, de outro, meio civilizado e refinado de exploração (MARX, 2004, p. 420).

Só é possível a realização desse comando efetivo - a subsunção real do trabalho ao capital, nas palavras de Marx, com a consolidação dos processos produtivos possibilitados pela Revolução Industrial, que deu seus primeiros passos no último terço do século XVIII, e tem suas bases na manufatura. É então que se instaura a produção especificamente capitalista, implementada através de máquinas (fundamentalmente através das máquinas-ferramenta) e típica da grande indústria (NETTO; BRAZ, 2007, p. 112). 
Assim, essa transformação atingiu um nível amplo e concretizou-se na Revolução Industrial. Esta deve ser entendida como um conjunto de transformações que ocorreram não só na indústria, mas nos transportes, comércio, etc. Representou em suma, o processo de mecanização das indústrias e a efetivação do modo de produção capitalista, dividindo a sociedade em duas classes básicas: a burguesia, proprietária dos meios de produção, e o proletariado, que só possui sua força de trabalho.

A maquinaria tornou-se o "meio para os capitalistas produzirem mais valia" (MARX, 1987, p. 424), pois no regime anterior não era mais possível obter os lucros desejados e, com ela, torna-se possível explorar ainda mais a força de trabalho, pois o trabalhador acaba sendo obrigado a vender sua força de trabalho por uma quantia muito pequena. Segundo Marx: "o emprego da maquinaria, como qualquer outro desenvolvimento da força produtiva do trabalho, tem por fim baratear as mercadorias [...] (MARX, 2004, p. 427) e não melhorar as condições de vida do trabalhador. Isso é compreensível, pois é da lógica de funcionamento desse modo de produção a ampliação dos lucros com a acumulação privada de capital. Nessa perspectiva, era necessário subverter os instrumentos de produção (manufatura para maquinofatura), para que o capital pudesse se reproduzir "livremente". Nesta modificação, ocorreu uma inversão nas posições determinantes para a produção de mercadorias, colocando o trabalhador simplesmente como um instrumento na cadeia produtiva e a máquina ocupando o seu lugar. Marx, ao analisar este processo, usa as seguintes palavras: "na manufatura, o ponto de partida para revolucionar o modo de produção é a força de trabalho, na indústria moderna, o instrumental de trabalho" (MARX, 1987, p.424).

Com a introdução da máquina-ferramenta, surge a necessidade de substituir a força humana por uma energia motriz, tornando-se imprescindível revolucionar a geração de energia que pudesse ocupar a força humana, pois esta limitava o funcionamento da grande máquina. A criação da máquina a vapor efetivou esse processo, pois o homem sendo considerado apenas uma força motriz numa máquina, passa a ser substituído por outro tipo de força (vento, vapor, etc). As novas tecnologias desqualificam o trabalho do homem, que assume o caráter de acidental na produção, e não é visto mais como necessário. 
A máquina- ferramenta, é portanto um mecanismo que, ao lhe ser transmitido o movimento apropriado, realiza com sua ferramentas as mesmas operações que eram antes realizadas pelo trabalhador com ferramentas semelhantes. Provenha a força motriz do homem ou de outra máquina, a coisa não muda em sua essência. Quando a ferramenta propriamente dita se transfere do homem para um mecanismo, a máquina toma o lugar da simples ferramenta. a Diferença salta aos olhos, mesmo quando o homem continua sendo o primeiro motor. [...] $O$ número de ferramentas com que opera simultaneamente a máquina ferramenta emancipa-se, desde o inicio, da barreira orgânica que a ferramenta manual de um trabalhador não podia ultrapassar (MARX, 1987, p. $426-427)$.

Revolucionando o modo de produção com a introdução da máquinaferramenta, a produção agora é executada por uma máquina e não depende mais, exclusivamente, do trabalhador e das suas ferramentas. Na produção mecanizada, o trabalhador é suprimido pela própria organização da produção, não prevalecendo os princípios subjetivos da divisão social do trabalho na manufatura (ARRUDA ANDRADE, 1988, p. 50).

Nesse sentido, Marx considerou:

Na manufatura, a organização do processo de trabalho é puramente subjetiva, uma combinação de trabalhadores parciais. No sistema de máquinas, tem a indústria moderna o organismo de produção inteiramente objetivo que o trabalhador encontra pronto e acabado como condição material da produção. $\mathrm{Na}$ cooperação simples e mesmo na cooperação fundada na divisão do trabalho, a supressão do trabalhador individualizado pelo trabalhador coletivizado parece ainda ser algo mais ou menos contingente. A maquinaria, com exceções a mencionar mais tarde, só funciona por meio de trabalho diretamente coletivizado ou comum. O caráter cooperativo do processo de trabalho torna-se uma necessidade técnica imposta pela natureza do próprio instrumental de trabalho (MARX, 2004, p. 442).

Por isso, na produção mecanizada, o trabalhador não detém o controle do processo de trabalho, ou seja, ele é obrigado a se adaptar ao processo de produção (e não mais o contrário, como acontecia na manufatura). A máquina passa a determinar o ritmo do trabalho e é responsável pela qualidade do produto. Também a quantidade de produção e o tempo de trabalho necessário à elaboração de um produto deixam de ser determinados pelo trabalhador. Ao analisar concretamente a produção mecanizada e suas consequências sobre o trabalhador, Marx destacou nos Grundrisse que: 
O processo de produção deixou de ser processo de trabalho no sentido de processo dominado pelo trabalho como unidade que o governa. Ao contrário, o trabalho aparece unicamente como órgão consciente, disperso em muitos pontos do sistema mecânico em forma de trabalhadores vivos individuais, subsumido ao processo total da própria maquinaria, ele próprio só um membro do sistema, cuja unidade não existe nos trabalhadores vivos, mas na maquinaria viva (ativa), que, diante da atividade isolada, insignificante do trabalhador, aparece como organismo poderoso. Na maquinaria, o trabalho objetivado se contrapõe ao trabalho vivo no próprio processo do trabalho como o poder que o governa, poder que, de acordo com sua forma, o capital é como apropriação do trabalho vivo. A assimilação do processo do trabalho como simples momento do processo de valorização do capital também é posta quanto ao aspecto material pela transformação do meio de trabalho em maquinaria e o trabalho vivo em mero acessório vivo dessa maquinaria, como meio de sua ação (MARX, 2011, p. 581).

Assim, o modo de produção capitalista tirou das mãos dos trabalhadores quase por completo o poder de produção, pois suplantou o ponto de partida da manufatura, que era a força de trabalho. Na maquinaria moderna, o trabalhador tornase um instrumento de trabalho e é engolido pelas novas invenções. $\mathrm{Na}$ indústria moderna, serve à máquina, não detendo mais o controle da produção, pois cabe a ele obedecer ao tempo e a velocidade que ela lhe impõe se quiser garantir sua sobrevivência.

Na maquinaria, o trabalho objetivado se contrapõe materialmente ao trabalho vivo como o poder dominante e como subsunção ativa deste a si, não só por meio da apropriação do trabalho vivo, mas no próprio processo real de produção (MARX, 2011, p. 581).

A rigor, pode se afirmar que a introdução das máquinas na produção foi o ponto decisivo em que o capitalismo tornou a força humana (seu trabalho), dispensável. Isso posto, pode-se entender que a passagem da produção manufatureira para a produção industrial em massa constitui-se no fator decisivo para o domínio de classe da burguesia e para a consolidação do modo de produção capitalista.

\section{CONSIDERAÇÕES FINAIS}

Pode-se concluir que com a passagem da manufatura para a indústria moderna, a partir século XVIII, permitiu a ampliação da produtividade do trabalho humano, mas o mesmo deixou de ser o fator determinante do processo. A introdução 
das máquinas no processo produtivo foi uma condição fundamental para que o capital pudesse subsumir realmente 0 trabalho aos seus interesses e dessa forma se reproduzir e se concentrar nas mãos de uma classe (burguesia), pois contribuiu com o barateamento da força de trabalho, com a ampliação do exército de reserva (desemprego) e com a fragilização do trabalho frente ao capital.

O domínio da burguesa (do capital) em relação aos operários não se deu simplesmente pelo uso da força, mas fundamentalmente com a implementação das novas tecnologias à produção, e, com ela, a ameaça do desemprego tornou-se um forte instrumento que a burguesia utilizou para atemorizar os proletários e enfraquecer suas lutas. Marx e Engels no Manifesto do Partido Comunista já compreendiam esse processo ao afirmar: "A burguesia não pode existir sem revolucionar continuamente os instrumentos de produção e, por conseguinte, as relações de produção, portanto todo o conjunto das relações sociais" (MARX; ENGELS, 1996, p.69). Por isso que a substituição da manufatura pela máquina na produção foi o ponto decisivo para o domínio de classe da burguesia e para a consolidação e manutenção do modo capitalista de produção.

Esse domínio do modo capitalista de produção não elimina as suas principais contradições (capital $X$ trabalho) e todas as transformações executadas pelo capital têm como objetivo a ampliação da taxa de lucro por meio da exploração da força de trabalho. Nesse sentido, argumenta Marx e Engels: "A condição mais essencial para a existência e a dominação da classe burguesa é a acumulação da riqueza nas mãos de particulares, a formação e o aumento do capital; a condição do capital é o trabalho assalariado" (1996, p. 77).

Enfim, o modo capitalista de produção tornou-se hegemônico com a passagem da manufatura para a indústria moderna, e para continuar seu domínio é necessário revolucionar constantemente os instrumentos de produção por meio do desenvolvimento tecnológico. Entretanto, esse processo não pode ser conduzido ao infinito, principalmente, porque ele se funda em bens finitos, como os recursos naturais e o próprio trabalho humano. Assim, não é possível o capital continuar se ampliando indefinidamente sem ampliar as suas contradições a patamares insustentáveis, o que 
nos permite pensar em sua superação ou na destruição completa de todos os recursos fundamentais para a vida humana.

\section{REFERÊNCIAS}

ARRUDA ANDRADE, José Jobson de. A Revolução Industrial. São Paulo: Ática, 1988.

JAPIASSU, Hilton. Dicionário Básico de Filosofia. Rio de Janeiro: Zahar, 1993.

MARX, Karl. Grundrisse: manuscritos econômicos de 1857 - 1858: esboços da crítica da economia política. São Paulo: Boitempo, 2011.

MARX, Karl. O Capital: crítica da economia política. São Paulo: Bertrand Brasil- DIFEL, 1987. 1.1, v. 1.

MARX, Karl. O Capital: crítica da economia política. São Paulo: Civilização Brasileira, 2004.

MARX, Karl. Capítulo Inédito do Capital. São Paulo: Escorpião, 1975.

MARX, Karl; ENGELS, F. A ideologia alemã. São Paulo: Boitempo, 2007.

MARX, Karl; ENGELS, Friedrich. Manifesto do partido comunista. Petrópolis: Vozes, 1996.

MAZZUCCHELLI, Frederico. A contradição e processo: o capitalismo e suas crises. São Paulo: Brasiliense, 1985.

MORAES NETO, Benedito Rodrigues de. Marx, Taylor, Ford: as forças produtivas em discussão. São Paulo: Brasiliense, 1989. 
NETTO, José Paulo; BRAZ, Marcelo. Economia política: uma introdução crítica. São Paulo: Cortez, 2007.

${ }^{1}$ Graduado em Filosofia, Mestre em Educação, Doutorando em Educação e Professor do Departamento de Ciências Sociais na Universidade Estadual do Paraná - Campus de Campo Mourão - PR. Email: msouza.32@gmail.com

${ }^{2}$ Doutor em História, Docente do programa de pós-graduação em Educação da Universidade Estadual de Maringá. Email: jjpmelo@hotmail.com

${ }^{3}$ Mestrando do Programa de Pós-Graduação em Educação da Universidade Estadual de Maringá. Email: billmchollow@gmail.com

${ }^{4}$ Filósofo alemão, nascido em Trier de família judia convertida ao Protestantismo. Sua obra teve grande impacto em sua época e na formação do pensamento social e político contemporâneo. Estudou direito nas Universidades de Bonn e de Berlim, doutorando-se na Universidade de lena (1841), com uma tese sobre a filosofia da natureza de Demócrito e de Epicuro. Ligou-se aos jovens hegelianos de esquerda, escrevendo em jornais socialistas. Depois de um intenso período de militância política, marcado pela fundação da liga dos comunistas (1847) e pela redação, com Engels, do Manifesto do Partido Comunista (1848), exilou-se na Inglaterra (1849), onde viveu até a sua morte, desenvolvendo as sua pesquisas e escrevendo grande parte de sua obra na biblioteca do Museu Britânico, em Londres. Suas principais obras são: A critica da filosofia do direito de Hegel (1843); A sagrada família (1845); A ideologia alemã (1845 - 1846); A miséria da filosofia: a resposta à filosofia da miséria de Proudhon (1847); A luta de classes na França (1850); Crítica da economia política (1859); O capital, 3 vols. (1867 - 1895). (JAPIASSU, 1993, p. 161).

${ }^{5}$ Chamo de mais-valia absoluta a produzida pelo prolongamento do dia de trabalho, e de mais-valia relativa a decorrente da contração do tempo de trabalho necessário e da correspondente alteração na | relação quantitativa entre ambas partes componentes da jornada de trabalho (MARX, 2004, p. 366).

RECEBIDO EM: 26.06 .2012

APROADO EM: 09.07.2012 